\title{
Is a treat-to-target strategy in osteoporosis applicable in clinical practice? Consensus among a panel of European experts
}

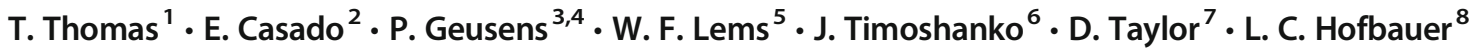

Received: 13 December 2019 / Accepted: 24 July 2020 / Published online: 7 August 2020

(C) The Author(s) 2020

\begin{abstract}
Summary A panel of European experts was convened to establish consensus on a treat-to-target strategy in osteoporosis. Panellists agreed that the ultimate goals of treating osteoporosis are recovering pre-fracture functional level and reducing subsequent fracture risk; there was consensus that total hip bone mineral density is currently the most appropriate treatment target in clinical practice.

Introduction A modified Delphi approach was convened to establish consensus among European experts on best practice management for patients with fragility fractures and whether a treat-to-target (T2T) strategy is applicable in osteoporosis.

Methods A panel of 12 clinical experts (from eight European countries) voted on 13 final statements relating to a T2T strategy for osteoporosis across three rounds of blinded, remotely conducted electronic surveys (Likert scale: 'strongly disagree', 'disagree', 'unable to answer', 'agree', 'strongly agree'). When panellists disagreed, they were asked how the statement could be adjusted to allow for a positive response, which was used to refine the statement for the following round. Consensus was defined as $\geq 75 \%$ agreement with a statement. Panellists were selected by UCB Pharma, which provided financial and logistical support.

Results Consensus was reached for 13/13 statements. Panellists agreed that the most important goals for fragility fracture patients are recovery of pre-fracture functional level and reduction of subsequent fracture risk. There was also consensus that a T2T strategy is applicable to osteoporosis and that bone mineral density (BMD) is currently the most clinically appropriate target. With regard to the definition of a specific BMD treatment target and timeframes applicable to T2T in osteoporosis, no clear consensus was reached; panellists emphasised that these would need to be individually determined.

Conclusions According to a panel of European experts, the main goals of fracture management are to recover pre-fracture functional level and reduce fracture risk. Total hip BMD seems to be the most clinically appropriate treatment target within a T2T strategy.
\end{abstract}

Keywords Bone mineral density $\cdot$ Delphi panel $\cdot$ Fragility fracture $\cdot$ Osteoporosis $\cdot$ Treat-to-target

Electronic supplementary material The online version of this article (https://doi.org/10.1007/s00198-020-05569-9) contains supplementary material, which is available to authorized users.

J. Timoshanko

jen.timoshanko@ucb.com

1 CHU de St-Etienne, INSERM U1059, Université de Lyon, St-Etienne, France

2 University Hospital Parc Taulí, Sabadell, Spain

3 Maastricht University, Maastricht, The Netherlands

4 Hasselt University, Hasselt, Belgium

5 Amsterdam University Medical Center, location VUmc, Amsterdam, The Netherlands

6 UCB Pharma, Slough, UK

7 Ogilvy Health, London, UK

8 Center for Healthy Aging \& Department of Medicine III, Technische Universität Dresden, Dresden, Germany

\section{Introduction}

Treat-to-target (T2T) is a proactive treatment strategy with a clear endpoint ('the target') and a commitment to change the therapy if the target is not achieved. In a T2T approach, the patient is reassessed periodically to see whether the target has been achieved [1-4]. T2T encourages physicians to assess treatment outcomes more often and revise treatments accordingly [1-3]. Additionally, T2T has potential to improve patients' treatment adherence, as patient buy-in and shared decision-making have been identified as essential components of a T2T approach $[2,5,6]$.

A T2T approach has been endorsed by professional organisations as a fundamental therapeutic strategy in type II diabetes and rheumatoid arthritis (RA) as, when applied, it yields improved outcomes to standard of care. The American Diabetes Association (ADA) and the European Association 
for the Study of Diabetes (EASD) recommend that glycated haemoglobin $\left(\mathrm{HbA}_{1 \mathrm{c}}\right)$ targets should be specified for individual patients and treatment should aim to bring $\mathrm{HbA}_{1 \mathrm{c}}$ values to those levels or lower, with treatment re-assessed and adjusted every 3-6 months [1]. In more recent applications of a T2T strategy in RA, the target has been identified as remission or low disease activity as defined by the European League Against Rheumatism (EULAR) [2]. Sustained use of a T2T strategy is associated with greater likelihood of remission in patients with RA [7]; in newly diagnosed patients, T2T may increase the odds of remission by around 50\% [8].

Based on its success in other chronic diseases, T2T is now being considered as a strategy for the management of osteoporosis, which remains underdiagnosed and undertreated despite enormous public health implications $[9,10]$. Notably, almost half of patients with a hip fracture have a history of a previous fragility fracture [11]. Approximately 2.7 million fragility fractures occurred across six European countries (France, Germany, Italy, Spain, Sweden and the UK) in 2017, and this is expected to rise as our population ages [10]. Despite their availability, utilisation of effective osteoporosis medications has declined further from already suboptimal levels in recent years [12].

While experts agree that the long-term goal of osteoporosis treatment is the prevention of new fractures [4], several knowledge gaps currently exist, including how to best manage patients at very high/imminent risk of fragility fracture and avoid the loss of independence, reduced quality of life and increased mortality that often follows a fracture $[13,14]$. There is little international consensus on specific, measurable, short-term osteoporosis treatment goals [4, 15], nor current sequential treatment recommendations that aim to reduce or prevent fragility fractures by targeting at-risk patients [15-17]. Treatment goals differ from clinically relevant treatment targets, which are biological markers that are highly correlated with the desired clinical outcome and can be used by physicians and patients to monitor treatment progress.

A T2T strategy in osteoporosis could help to address the unmet needs in fracture management by identifying a suitable treatment target, individualizing the initial treatment choice and guiding shared decision-making. Given the low treatment adherence rates in osteoporosis [18, 19], a T2T approach could increase patient engagement, improving adherence and therefore outcomes [17, 20, 21]. In 2018, a Spanish expert panel established the applicability of a T2T strategy for osteoporosis, including therapeutic objectives, patient follow-up, treatment failure criteria and appropriate treatment use [20]. The American Society for Bone and Mineral Research-US National Osteoporosis Foundation (ASBMR-NOF) working group also supports a T2T approach in osteoporosis and recommends several principles to guide treatment selection and monitoring, for example, considering more potent initial treatment in patients with high risk of fracture [4]. Clinical measures that could potentially be used as a target include bone mineral density (BMD) T-score, fracture risk assessment tool (FRAX) score, bone turnover markers (BTMs) and the absence of new fractures $[4,15,20]$.

In this study, a modified Delphi approach was conducted to develop consensus among European experts on best practice for the management of fragility fractures and to determine whether a T2T strategy would be appropriate for osteoporosis patients with a fragility fracture.

\section{Methods}

\section{Delphi panel participants and design}

Twenty-three clinicians with expertise in bone metabolism and fragility fractures were invited to participate in a modified Delphi panel examining different aspects of fragility fracture management in osteoporosis. Invited clinicians were selected based on several criteria related to their expertise in osteoporosis, including experience with the T2T approach in fragility fracture management, as well as relevant committee/guideline involvement and authorship of relevant publications. Further, country and medical specialty (to ensure a range of European countries and specialties were represented) and knowledge of the Delphi process was considered when selecting clinicians to invite.

Ogilvy Health was paid by UCB Pharma to conduct this study, and coordinated the Delphi panel preparation, voting rounds and data management, independent of UCB Pharma (Fig. 1). Panellists received honoraria from UCB Pharma for their participation in the Delphi panel, though there was no interference in respondents' free communication and dissemination of the Delphi panel results. Two panel chairs (TT and LH) were selected, based on the same criteria used to invite clinicians, to provide input on the initial statements following a literature review of articles describing a T2T strategy. Three rounds of blinded, remotely conducted electronic surveys were distributed among participants, with panel chairs reviewing and providing input on the draft questions before each round. The number of rounds was pre-specified, with the option to resolve any outstanding issues via teleconference before proceeding to a final survey following the third round, although this was not required.

During each round, panellists were asked to vote on individual statements using a Likert scale, choosing between 'strongly disagree', 'disagree', 'unable to answer', 'agree' or 'strongly agree' for each statement. Consensus was defined as $\geq 75 \%$ agreement with a statement. During the first two rounds, panellists were also asked to respond to exploratory questions, and these results were used to inform the statements in the following round(s) (Fig. 1).

Where panellists selected 'disagree' or 'strongly disagree', they were asked to provide information on why they disagreed and how the statement could be adjusted to allow for a positive 
Literature review and teleconference with panel chairs to define the

objectives and activities of the study and initial consensus statements
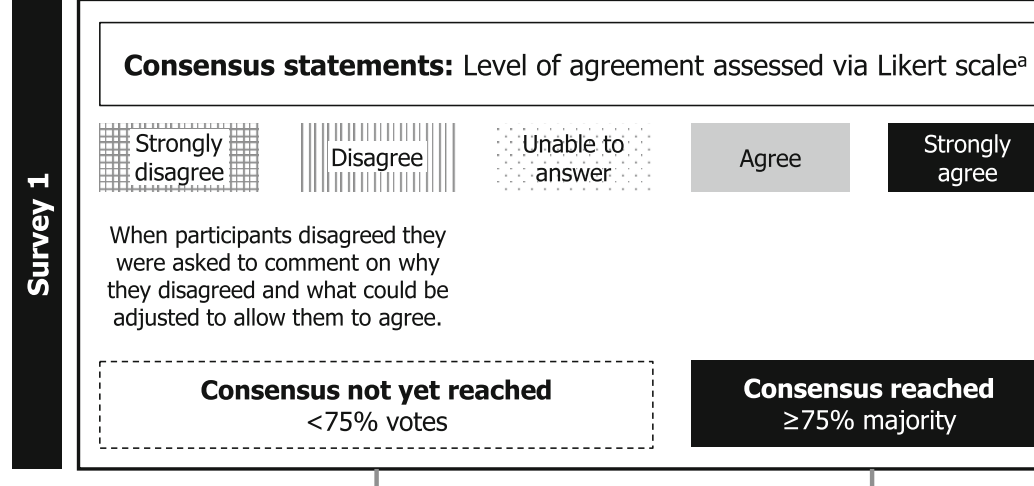

Additional exploratory questions: Multiple-

choice answers depended on specific questions ${ }^{b}$

When participants disagreed they

were asked to comment on why

they disagreed and what could be adjusted to allow them to agree.

Consensus not yet reached $<75 \%$ votes

Consensus reached $\geq 75 \%$ majority



Consensus statements: Level of agreement assessed via Likert scale ${ }^{a, c}$

Additional exploratory questions $^{b}$

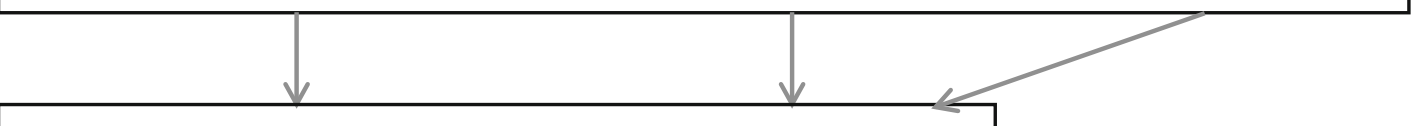

Consensus statements: Level of agreement assessed via Likert scalea,c

Fig. 1 Delphi panel study design ${ }^{\mathrm{a}}$, a Panellists were asked to vote for one answer (choice between 'strongly disagree', 'disagree', 'unable to answer', 'agree' or 'strongly agree') across three rounds of blinded, remotely conducted esurveys, and the level of consensus for 13 final statements was assessed. Consensus was defined as $\geq 75 \%$ agreement with a statement. b Responses to exploratory questions were used to

response. This information was then used to refine the statement, with some adjustments made to avoid repetition of statements. The revised statement was then included at the next survey round. To increase the strength of consensus, some statements already achieving consensus were also refined and re-voted upon, based on comments from the panellists.

Here, we focus on 13 final statements relating to a T2T approach for osteoporosis, including four statements on goals of fragility fracture management, five statements on T2T applicability in osteoporosis and four statements on specific treatment targets.

\section{Results}

\section{Delphi panel participants and characteristics}

Twelve of the $23(52.2 \%)$ clinicians participated in the panel. Eleven clinicians did not respond to the invitation. The resulting group included panellists from eight European refine consensus statements, and additional exploratory questions were developed and posed to panellists. c Consensus statements were refined and re-voted upon if consensus was not reached in the previous round. Some statements which had already reached consensus were also refined and re-voted upon based on improvements suggested by panellists in order to increase the strength of consensus

countries (Belgium, Denmark, France, Germany, Italy, The Netherlands, Spain and the UK) and included five rheumatologists, five endocrinologists and two orthopaedic surgeons.

\section{Degree of consensus}

Every survey question was answered by all panellists across three rounds of voting (Suppl 1). Consensus was reached for $13 / 13$ statements $(100 \%)$.

\section{Goals of fragility fracture management}

All panellists (100\%) agreed that for physicians, the two most important management goals for patients who have experienced a fragility fracture are to maximise recovery of prefracture functional level and to prevent new fractures (Statement 1) (Fig. 2). There was also agreement that specific treatment goals should be determined according to the patients' individual problems or concerns (Statement 2; $91.7 \%$ 


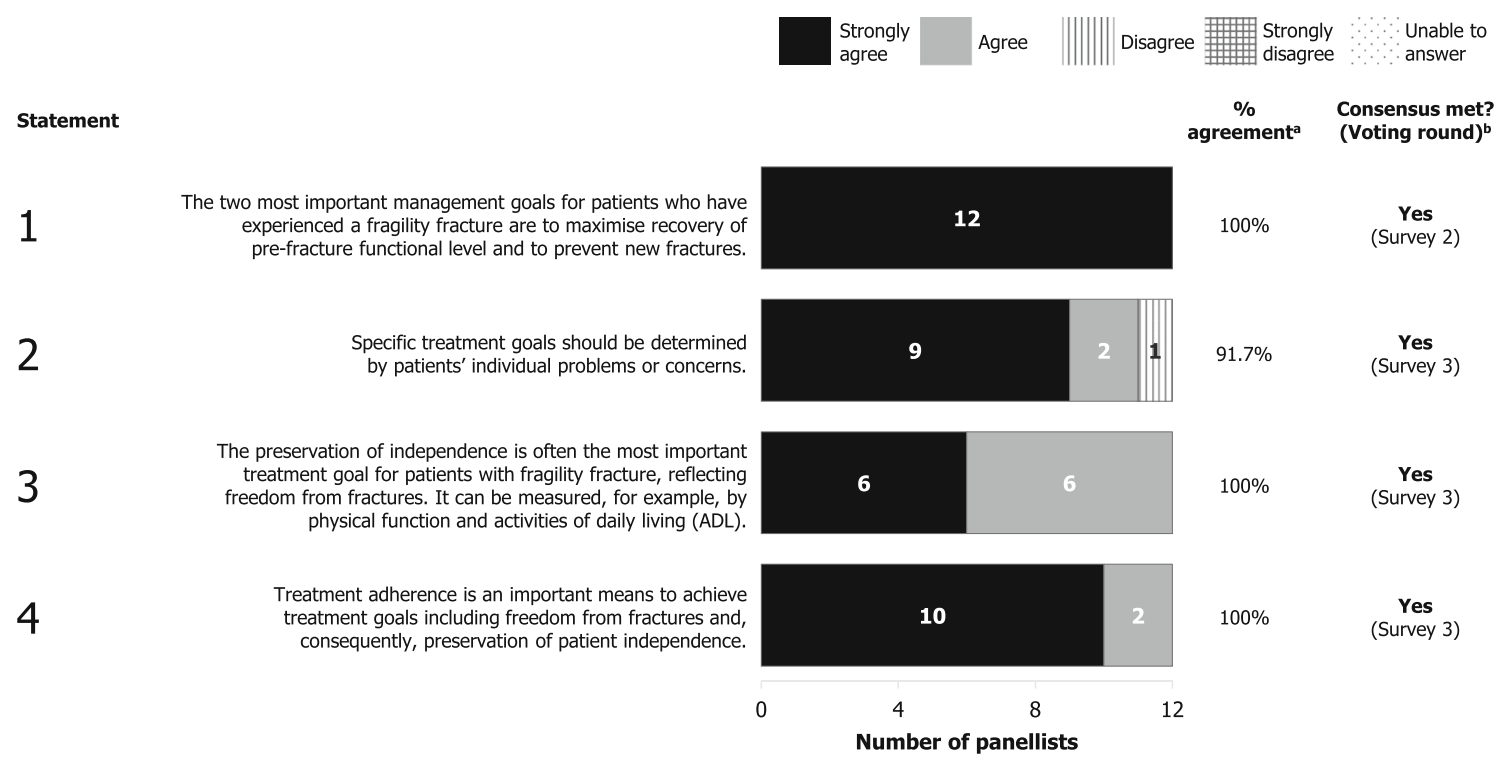

Fig. 2 Results from statements related to goals of fragility fracture management: a \% agreement indicates the percentage of panellists responding 'agree' or 'strongly agree', with consensus defined as $\geq 75 \%$ agreement, and $\mathbf{b}$ all statements met consensus by the third round of voting. ADL activities of daily living

agreement), and panellists advocated for individualisation of treatment. For instance, in a patient with a good previous functional level but with a very low BMD, the goal should be focused on BMD; while in a patient with previously limited mobility and multiple fractures but not very low BMD, the goal should first be focused on frailty and functional rehabilitation for avoiding falls and new fractures.

All panellists (100\%) agreed that the preservation of independence is often the most important goal for patients with fragility fracture, reflecting freedom from fractures, which can be measured by physical function and activities of daily living (ADL) questionnaires (Statement 3), and that adherence to treatment is crucial for achieving fracture prevention, and subsequently preserving patient independence (Statement 4).

\section{Applicability of T2T to osteoporosis}

All panellists (100\%) agreed that the best approach to achieve management goals for fragility fractures is to set a treatment target and make therapeutic decisions based on the probability of reaching that target (Statement 5) (Fig. 3). It was also agreed in the first round of voting that a treatment target representing achievement of an acceptable level of fracture risk would have value in clinical practice (Statement 6; 91.7\% agreement).

Panellists agreed that a single overarching target of 'low fracture risk' (from clinical and/or screening tests) can be established for most post-fracture patients that would require different approaches to achieve; however, this will not be feasible for some patients who require a personalised target (Statement 7; 91.7\% agreement). Furthermore, all panellists $(100 \%)$ agreed that truly goal-directed treatment plans, which best work towards the overall goal of fracture prevention and achieve the BMD treatment target, will require more potent therapies than are currently available (Statement 8 ). This statement was developed after panellists indicated during the second round that antiresorptives would be the best first-line, one-size-fits-all therapy available at the time of the survey, but that individualisation would still be required as the fracture rate would still be too high with antiresorptives alone. They also agreed that there is a need for practical guidelines on how to use different treatments in patients with fragility fracture, including in what sequence, with what aim/target and in which patients (Statement 9).

\section{Specific treatment targets for T2T in osteoporosis}

BMD, assessed via dual-energy X-ray absorptiometry (DXA) scan, was agreed to be the most clinically appropriate treatment target for most fragility fracture patients as it is the best available surrogate of fracture risk (Statement 10; 91.7\% agreement) (Fig. 4). The panellists also agreed that the target $\mathrm{T}$-score should be set at a level associated with no increase in risk of fracture for the same age population, taking also into account the patient characteristics, and selecting a reasonable and achievable value (Statement 11; 75.0\% agreement) and that the timepoint at which to assess whether the treatment target has been achieved should be established on an individual basis after starting treatment (Statement 12; 83.3\% agreement). Furthermore, it was agreed that the frequency of BMD monitoring is dependent on the type of treatment (Statement $13 ; 83.3 \%$ agreement).

During the second round, panellists were asked multiplechoice questions on the most appropriate total hip BMD T- 




Fig. 3 Results from statements related to applicability of T2T to osteoporosis: a \% agreement indicates the percentage of panellists responding 'agree' or 'strongly agree', with consensus defined as $\geq 75 \%$ agreement, and $\mathbf{b}$ all statements met consensus by the third round of voting. BMD bone mineral density

score target and optimal BMD monitoring frequency for the majority of patients. However, consensus was not reached for either item (Fig. 5). For the total hip BMD T-score, panellists were asked to choose from three options: -1.0 to $-1.5,-2.0$ or -2.5 ; resulting votes were $33.3 \%, 41.7 \%$ and $25.0 \%$, respectively (Fig. 5a). While $58.3 \%$ of panellists agreed that the optimal BMD monitoring frequency would be every 2 3 years, consensus was not achieved (Fig. 5b).



Fig. 4 Results from statements related to specific treatment targets for T2T in osteoporosis: a $\%$ agreement indicates the percentage of panellists responding 'agree' or 'strongly agree', with consensus
The responses on the most appropriate total hip BMD T-score treatment target (Fig. 5a) led to the incorporation of a BMD range of -2.5 to -1.0 at the total hip into Statement 11. Additionally, Statement 13 was revised to indicate that monitoring frequency should be dependent on the treatment choice, based on comments from the panellists in response to that question. Statements 12 and 13, taken together, indicate that the

defined as $\geq 75 \%$ agreement, and $\mathbf{b}$ all statements met consensus by the third round of voting. BMD bone mineral density, DXA dualenergy X-ray absorptiometry 

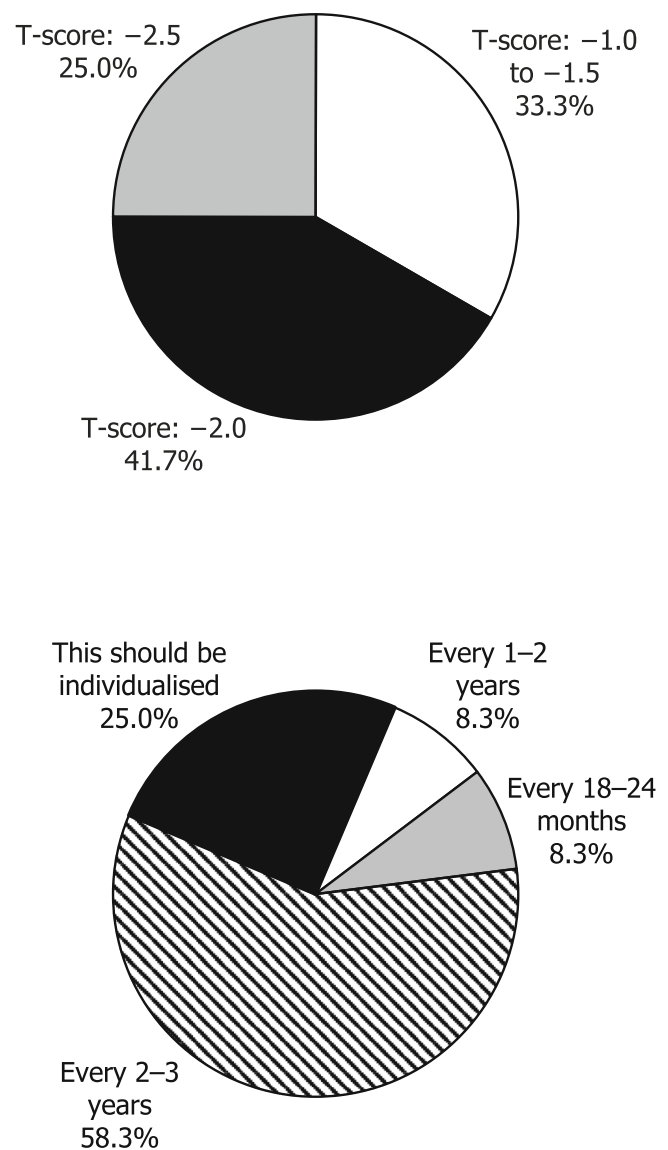

Fig. 5 Panellist responses on the most clinically appropriate total hip BMD T-score treatment target and BMD monitoring frequency: a Please select the specific BMD T-score below you believe to be the most clinically appropriate treatment target (i.e. can be established for most patients) and b Please select the frequency of BMD monitoring you believe to be the most clinically appropriate. BMD bone mineral density

frequency of BMD monitoring would depend on the drug and patient characteristics.

\section{Discussion}

This study establishes opinion among European experts regarding the use of a T2T strategy in osteoporosis and provides further support for this type of approach in patients with a history of fragility fracture. The expert panel agreed that the most important management goals for patients with a fragility fracture are the recovery of pre-fracture functional level and the reduction of subsequent fracture risk and that a T2T strategy is applicable and could be beneficial to patients with a history of fragility fracture. According to the expert panel, BMD is currently the most clinically appropriate treatment target as it is the most accessible clinical measure of bone strength. This panel focused on patients with a prior fragility fracture as many patients do not realise that they have osteoporosis and are at risk until they experience their first symptomatic fracture [9, 22], after which point use of a target BMD during treatment decisions becomes more applicable. However, logic follows that a T2T approach may also be suitable in patients with low BMD and no history of fracture, if these patients are identified early enough after developing osteoporosis. Targeting BMD may support the main goals experts established for these patients: recovery of prefracture functional level and reduced fracture risk. Improving BMD would decrease the risk of fractures, dramatically impacting patient ADLs and improving quality of life.

While all 13 statements reached consensus within the three voting rounds, those related to specific treatment targets for $\mathrm{T} 2 \mathrm{~T}$ in osteoporosis (Statements 10-13) reached a lower level of agreement than Statements 1-9, which consistently achieved $\geq 90 \%$ agreement. Statements relating to the targeted BMD Tscore, the timepoint to assess the target achievement and the frequency of BMD monitoring reached 75-83\% agreement. When asked to select a specific BMD T-score, there was no agreement and the expert panel discussed the need for individualised targets, since these values are likely to differ between patients depending on various circumstances: BMD $\mathrm{T}$-score at the beginning of treatment and the presence of other risk factors for future fracture (independent from BMD) are two demonstrative examples. Recent data from some clinical trials suggest that, regardless of age or previous vertebral fracture(s), a patient will remain at high risk of future fracture until a total hip BMD T-score of -1.5 is reached [23, 24]. Therefore, while individualised targets are likely necessary, it is possible that a BMD T-score target of -1.5 may be appropriate for many, though would still need to be individualised based on the patient's BMD at the start of therapy. Even with bone-forming agents (which provide optimal outcomes in severe osteoporosis), BMD can only be increased to a certain extent, so in the management of osteoporosis, it seems reasonable to consider both patient and clinician expectations. In fact, T2T guidelines in rheumatology incorporate physician- and patient-shared decision-making as part of the strategy, involving disease risks, treatment risks and benefits, treatment targets and a management plan [2]. It is unknown whether collaborative shared decision-making is feasible in a T2T approach in osteoporosis; this is an area for future research. It may be more difficult in osteoporosis partly due to the known discrepancies between how patients and practitioners perceive fracture risk $[25,26]$. A previous study in RA patients found that patients' willingness to change is directly associated with their disease activity scores [27], but this seems difficult to leverage in a disease like osteoporosis in which patients may not have yet experienced a fracture or have no complaints of back pain (as associated with vertebral fractures). The ethos of shared decisionmaking to ensure patients have an active role in treatment choice would remain the same, however [28], and would therefore not leave the patient at the mercy of the treating physician alone. 
The results reported here are consistent with the outcomes of the Spanish Delphi panel and ASBMR-NOF working group $[4,20]$. Both groups concluded that a T2T approach is applicable in osteoporosis and set the therapeutic objectives as absence of new fractures, including those that do not present clinically, increase in BMD and reduction in FRAX risk score $[4,20]$. In order to integrate the occurrence of morphometric vertebral fractures into a T2T strategy, it will be necessary to improve diagnoses of these fractures in order to accurately assess progress towards the treatment goal. Further research in this area is needed.

Previous studies have demonstrated that both BMD and FRAX can predict risk of future fragility fractures and that BMD improvements on treatment are associated with reduced fracture risk [23, 29-31]. While the Spanish experts and the ASBMR-NOF working group established specific target BMD T-scores $(>-2.5$ for lumbar spine or total hip and $>-2.5$ or $>-2.0$ for the femoral neck) $[4,20]$, this panel was unable to reach agreement on this topic. Additionally, while consensus on BMD monitoring frequency was not reached in this study, every ' $2-3$ years' received the most votes. This is aligned with the outcomes of the Spanish Delphi panel, which suggest that the treatment failure criteria should be failure to achieve the target BMD Tscore or occurrence of a new fracture within 2-3 years [20]. Here, panellists were asked in round 1 which treatment target would be the most appropriate. Since there was a strong consensus for BMD, this was the focus throughout the following surveys, and therefore, other possible targets were not discussed in the following rounds (e.g. FRAX score, BTMs, absence of fractures). Although there was great agreement among panellists that there is a need for clinical guidelines on how to select or sequence osteoporosis treatment in patients with a fragility fracture in a T2T strategy, they did not discuss the optimal treatment strategy in every clinical scenario (Statement 9). The importance of treatment sequence has been addressed in previous literature [32,33], and would be a good topic for future consensus.

A European Society for Clinical and Economic Aspects of Osteoporosis, Osteoarthritis and Musculoskeletal Diseases (ESCEO) working group also highlighted the importance of establishing an international consensus on intervention thresholds and a universally accepted definition of treatment failure [15]. However, the results of this Delphi panel indicate that the individualisation of treatment selection, goals and monitoring frequency should be considered in the management of fragility fracture patients.

\section{Study strengths and limitations}

The systematic Delphi process, utilizing clinical opinion from a group of selected experts in osteoporosis, was chosen as it was thought to be the most appropriate strategy to develop clinical recommendations. The anonymous nature of the surveys allowed for unbiased responses from panellists. However, there are no universal guidelines indicating how a Delphi panel should be conducted, and it has been suggested that psychosocial factors may lead experts with divergent views to conform so that consensus is reached [34]; this may have impacted our results.

This study presents a wide, geographically dispersed opinion on osteoporosis from experts from eight European countries. However, the panel only included a small number of bone physicians, which may have limited the breadth of advice. It may be beneficial in further exploration of these topics to include experts from other fields and specialties (e.g. epidemiologists) and, when new osteoanabolic drugs are available and when T2T is a well-known opportunity in the field of osteoporosis, also patients. The experts in this panel were also only asked for their agreement, rather than their separate wishes and prognosis perspectives, on treatment goals and targets. However, due to the statements being revised between rounds, they are representative of the panellists' varied opinions. Furthermore, as published evidence for T2T on improving outcomes in osteoporosis patients currently is limited, only clinical opinion was utilised when developing the consensus statements. Lastly, statements around the applicability of T2 $\mathrm{T}$ in osteoporosis focused on DXA measures and did not account for the results of vertebral fracture assessment, which is certainly also an important predictor of future fractures.

\section{Conclusion}

This study provides strong support among European experts for the value of a T2T strategy in osteoporosis. Although recovery of pre-fracture functional level and a reduction of fracture risk are the main goals, BMD seems an appropriate treatment target, echoing similar findings from Spain and the USA. Although BMD T-score cut-off and assessment timeframes remain undefined, individualisation of treatment and establishing an achievable target in each patient will likely help to close the gap in osteoporosis. Further research is needed to better establish guidelines on BMD monitoring, treatment failure, treatment sequence and the duration of pharmacological treatment.

Acknowledgements The authors acknowledge Helen Chambers, PhD, Costello Medical, UK for publication coordination and Kristian Clausen, MPH, Madeleine Warner, $\mathrm{PhD}$, and Simon Foulcer, $\mathrm{PhD}$ from Costello Medical, UK, for medical writing and editorial assistance based on the authors' input and direction. The authorship would also like to thank those experts that participated in the panel in addition to those acting as authors here: Bernard Cortet, Adolfo Díez-Pérez, Andreas Kurth, Eugene McCloskey, Salvatore Minisola, Henrik Palm and Joop Van den Bergh. All the panellists received honoraria from UCB Pharma for participating in the Delphi panel. 
Funding information This study was sponsored by UCB Pharma and Amgen Inc. Support for study conception and design, acquisition of data, and analysis and interpretation of data, provided by Ogilvy Health, was funded by UCB Pharma and Amgen Inc. Support for third-party writing assistance for this article, provided by Kristian Clausen, MPH, Madeleine Warner, PhD, and Simon Foulcer, PhD, Costello Medical, UK was funded by UCB Pharma and Amgen Inc. in accordance with Good Publication Practice (GPP3) guidelines (http://www.ismpp.org/gpp3).

\section{Compliance with ethical standards}

\section{Conflicts of interest None.}

Disclosures TT: consultant/speaker for AbbVie, Amgen Inc., Arrow, Biogen, Bristol-Myers Squibb, Chugai, Expanscience, Gilead, Grunenthal, HAC Pharma, LCA, Lilly, Medac, Merck Sharp \& Dohme, Novartis, Pfizer, Thuasne, Teva and UCB Pharma; received financial support or fees for research activities from Amgen Inc., Bone Therapeutics, Chugai, HAC Pharma, Merck Sharp \& Dohme, Novartis, Pfizer and UCB Pharma; EC: speaker for Amgen Inc., Lilly and Rubió; received advisory board honoraria from Stada, Theramex and UCB Pharma; PG: received advisory board honoraria from UCB Pharma; WL: received advisory board honoraria from Amgen Inc., Eli Lilly and UCB Pharma; JT: employed by and stockholder of UCB Pharma; DT: employed by Ogilvy Health at the time of the study and funded by UCB Pharma and Amgen Inc. to conduct this study; LCH: received advisory board honoraria from Alexion, Amgen Inc., Kyowa Kirin International, Shire and UCB Pharma.

Open Access This article is licensed under a Creative Commons Attribution-NonCommercial 4.0 International License, which permits any non-commercial use, sharing, adaptation, distribution and reproduction in any medium or format, as long as you give appropriate credit to the original author(s) and the source, provide a link to the Creative Commons licence, and indicate if changes were made. The images or other third party material in this article are included in the article's Creative Commons licence, unless indicated otherwise in a credit line to the material. If material is not included in the article's Creative Commons licence and your intended use is not permitted by statutory regulation or exceeds the permitted use, you will need to obtain permission directly from the copyright holder. To view a copy of this licence, visit http://creativecommons.org/licenses/by-nc/4.0/.

\section{References}

1. Davies MJ, D'Alessio DA, Fradkin J, Kernan WN, Mathieu C, Mingrone G, Rossing P, Tsapas A, Wexler DJ, Buse JB (2018) Management of hyperglycaemia in type 2 diabetes, 2018. A consensus report by the American Diabetes Association (ADA) and the European Association for the Study of Diabetes (EASD). Diabetologia 61:2461-2498

2. Smolen JS, Landewe R, Bijlsma J, Burmester G, Chatzidionysiou K, Dougados M, Nam J, Ramiro S, Voshaar M, van Vollenhoven $\mathrm{R}$, Aletaha D, Aringer M, Boers M, Buckley CD, Buttgereit F, Bykerk V, Cardiel M, Combe B, Cutolo M, van Eijk-Hustings Y, Emery P, Finckh A, Gabay C, Gomez-Reino J, Gossec L, Gottenberg JE, Hazes JMW, Huizinga T, Jani M, Karateev D, Kouloumas M, Kvien T, Li Z, Mariette X, McInnes I, Mysler E, Nash P, Pavelka K, Poor G, Richez C, van Riel P, Rubbert-Roth A, Saag K, da Silva J, Stamm T, Takeuchi T, Westhovens R, de Wit M, van der Heijde D (2017) EULAR recommendations for the management of rheumatoid arthritis with synthetic and biological disease-modifying antirheumatic drugs: 2016 update. Ann Rheum Dis 76:960-977

3. Wailoo A, Hock ES, Stevenson M, Martyn-St James M, Rawdin A, Simpson E, Wong R, Dracup N, Scott DL, Young A (2017) The clinical effectiveness and cost-effectiveness of treat-to-target strategies in rheumatoid arthritis: a systematic review and costeffectiveness analysis. Health Technol Assess 21:1-258

4. Cummings SR, Cosman F, Lewiecki EM, Schousboe JT, Bauer DC, Black DM, Brown TD, Cheung AM, Cody K, Cooper C, Diez-Perez A, Eastell R, Hadji P, Hosoi T, Jan De Beur S, Kagan R, Kiel DP, Reid IR, Solomon DH, Randall S (2017) Goal-directed treatment for osteoporosis: a progress report from the ASBMRNOF working group on goal-directed treatment for osteoporosis. J Bone Miner Res 32:3-10

5. Bacalao EJ, Greene GJ, Beaumont JL, Eisenstein A, Muftic A, Mandelin AM, Cella D, Ruderman EM (2017) Standardizing and personalizing the treat to target (T2T) approach for rheumatoid arthritis using the Patient-Reported Outcomes Measurement Information System (PROMIS): baseline findings on patientcentered treatment priorities. Clin Rheumatol 36:1729-1736

6. Colombel J-F, D'haens G, Lee W-J, Petersson J, Panaccione R (2019) Outcomes and strategies to support a treat-to-target approach in inflammatory bowel disease: a systematic review. J Crohn's Colitis 14:254-266

7. Ramiro S, Landewé RB, van der Heijde D, Sepriano A, FitzGerald O, Ostergaard M, Homik J, Elkayam O, Thorne JC, Larche M, Ferraccioli G, Backhaus M, Boire G, Combe B, Schaeverbeke T, Saraux A, Dougados M, Rossini M, Govoni M, Sinigaglia L, Cantagrel AG, Allaart CF, Barnabe C, Bingham CO, Tak PP, van Schaardenburg D, Hammer HB, Dadashova R, Hutchings E, Paschke J, Maksymowych WP (2020) Is treat-to-target really working in rheumatoid arthritis? A longitudinal analysis of a cohort of patients treated in daily practice (RA BIODAM). Ann Rheum Dis 79:453-459

8. Vermeer M, Kuper HH, Hoekstra M, Haagsma CJ, Posthumus MD, Brus HL, van Riel PL, van de Laar MA (2011) Implementation of a treat-to-target strategy in very early rheumatoid arthritis: results of the Dutch Rheumatoid Arthritis Monitoring remission induction cohort study. Arthritis Rheum 63:2865-2872

9. Lems WF, Raterman HG (2017) Critical issues and current challenges in osteoporosis and fracture prevention. An overview of unmet needs. Ther Adv Musculoskelet Dis 9:299-316

10. International Osteoporosis Foundation (2018) Broken bones, broken lives: a roadmap to solve the fragility fracture crisis in Europe http://share.iofbonehealth.org/EU-6-Material/Reports/IOF\% 20Report_EU.pdf Accessed 11 November 2019

11. McLellan AR, Reid DM, Forbes K, Reid R, Campbell C, Gregori A, Raby N, Simpson A (2004) Effectiveness of strategies for the secondary prevention of osteoporotic fractures in Scotland (CEPS: 99/03). NHS Quality Improvement Scotland

12. Wysowski DK, Greene P (2013) Trends in osteoporosis treatment with oral and intravenous bisphosphonates in the United States, 2002-2012. Bone 57:423-428

13. Leder BZ, Clarke BL, Shane E, Khosla S, Kiel DP (2019) A lot of progress, with more to be one: a response to NIH pathways to prevention report "Research Gaps for Long-Term Drug Therapies for Osteoporotic Fracture Prevention”. J Bone Miner Res 34:15491551

14. Bliuc D, Nguyen ND, Milch VE, Nguyen TV, Eisman JA, Center JR (2009) Mortality risk associated with low-trauma osteoporotic fracture and subsequent fracture in men and women. JAMA 301: 513-521

15. Kanis JA, McCloskey E, Branco J, Brandi ML, Dennison E, Devogelaer JP, Ferrari S, Kaufman JM, Papapoulos S, Reginster JY, Rizzoli R (2014) Goal-directed treatment of osteoporosis in Europe. Osteoporos Int 25:2533-2543 
16. Lems W, Dreinhofer K, Bischoff-Ferrari H, Blauth M, Czerwinski E, da Silva J, Herrera A, Hoffmeyer P, Kvien T, Maalouf G, Marsh D, Puget J, Puhl W, Poor G, Rasch L, Roux C, Schuler S, Seriolo B, Tarantino U, van Geel T, Woolf A, Wyers C, Geusens P (2017) EULAR/EFORT recommendations for management of patients older than 50 years with a fragility fracture and prevention of subsequent fractures. Ann Rheum Dis 76:802-810

17. Lewiecki EM, Cummings SR, Cosman F (2013) Treat-to-target for osteoporosis: is now the time? J Clin Endocrinol Metab 98:946953

18. Warriner AH, Curtis JR (2009) Adherence to osteoporosis treatments: room for improvement. Curr Opin Rheumatol 21:356-362

19. (2005) The adherence gap: Why osteoporosis patients don't continue with treatment. https://www.iofbonehealth.org/sites/default/ files/PDFs/adherence gap_report_2005.pdf. Accessed 4 Aug 2020

20. Nogues X, Nolla JM, Casado E, Jodar E, Munoz-Torres M, Quesada-Gomez JM, Canals L, Balcells M, Lizan L (2018) Spanish consensus on treat to target for osteoporosis. Osteoporos Int 29:489-499

21. Hernlund E, Svedbom A, Ivergard M, Compston J, Cooper C, Stenmark J, McCloskey EV, Jonsson B, Kanis JA (2013) Osteoporosis in the European Union: medical management, epidemiology and economic burden. A report prepared in collaboration with the International Osteoporosis Foundation (IOF) and the European Federation of Pharmaceutical Industry Associations (EFPIA). Arch Osteoporos 8:136

22. Miller PD (2016) Underdiagnosis and undertreatment of osteoporosis: the battle to be won. J Clin Endocrinol Metab 101:852-859

23. Ferrari S, Libanati C, Lin CJF, Brown JP, Cosman F, Czerwinski E, de Gregomicronrio LH, Malouf-Sierra J, Reginster JY, Wang A, Wagman RB, Lewiecki EM (2019) Relationship between bone mineral density t-score and nonvertebral fracture risk over 10 years of denosumab treatment. J Bone Miner Res 34:1033-1040

24. Cosman F, Lewiecki EM, Ebeling PR, Hesse E, Napoli N, Crittenden DB, Rojeski M, Yang W, Libanati C, Ferrari S (2018) $\mathrm{T}$-score as an indicator of fracture risk on therapy: evidence from romosozumab vs alendronate treatment in the $\mathrm{ARCH}$ trial. J Bone Miner Res 33:25
25. Langer FW, da Silveira Codevilla AA, Bringhenti R, Dal Osto LC, Campos TR, Martins TT, Barin AE, Rigo PH, Boufleuer ND, Santinon SF, Kipper K, Rodrigues J, Premaor MO (2016) Low self-awareness of osteoporosis and fracture risk among postmenopausal women. Arch Osteoporos 11:27

26. Kalluru R, Petrie KJ, Grey A, Nisa Z, Horne AM, Gamble GD, Bolland MJ (2017) Randomised trial assessing the impact of framing of fracture risk and osteoporosis treatment benefits in patients undergoing bone densitometry. BMJ Open 7:e013703

27. van Hulst LT, Kievit W, van Bommel R, van Riel PL, Fraenkel L (2011) Rheumatoid arthritis patients and rheumatologists approach the decision to escalate care differently: results of a maximum difference scaling experiment. Arthritis Care Res 63:1407-1414

28. Cornelissen D, Boonen A, Bours S, Evers S, Dirksen C, Hiligsmann M (2020) Understanding patients' preferences for osteoporosis treatment: the impact of patients' characteristics on subgroups and latent classes. Osteoporos Int 31:85-96

29. Marshall D, Johnell O, Wedel H (1996) Meta-analysis of how well measures of bone mineral density predict occurrence of osteoporotic fractures. BMJ 312:1254-1259

30. Leslie WD, Majumdar SR, Lix LM, Morin SN, Johansson H, Oden A, McCloskey EV, Kanis JA (2014) Can change in FRAX score be used to "treat to target"? A population-based cohort study. J Bone Miner Res 29:1074-1080

31. Bouxsein ML, Eastell R, Lui LY, Wu LA, de Papp AE, Grauer A, Marin F, Cauley JA, Bauer DC, Black DM (2019) Change in bone density and reduction in fracture risk: a meta-regression of published trials. J Bone Miner Res 34:632-642

32. Cosman F, Nieves JW, Dempster DW (2017) Treatment sequence matters: anabolic and antiresorptive therapy for osteoporosis. J Bone Miner Res 32:198-202

33. Leder BZ (2018) Optimizing sequential and combined anabolic and antiresorptive osteoporosis therapy. JBMR plus 2:62-68

34. Keeney S, Hasson F, McKenna H (2011) The Delphi technique in nursing and health research. John Wiley \& Sons, Chichester

Publisher's note Springer Nature remains neutral with regard to jurisdictional claims in published maps and institutional affiliations. 